\title{
Determination of the amount of irrigation water for cucumber (Cucumis sativus L.) grown on four types of substrate
}

\author{
Nguyen H. Pham*, Hung T. Huynh, \& Dung T. Nguyen \\ Faculty of Agronomy, Nong Lam University, Ho Chi Minh City, Vietnam
}

\begin{abstract}
ARTICLE INFO
Research Paper

Received: January 31, 2018

Revised: May 07, 2018

Accepted: May 10, 2018

\section{Keywords}

Cucumber

Evapotranspiration (ETc)

Soilless culture

Substrate

The amount of irrigated water
\end{abstract}

\section{${ }^{*}$ Corresponding author}

Pham Huu Nguyen

Email: phnguyen@hcmuaf.edu.vn

\begin{abstract}
There are many types of substrate used in soilless cultivation, but each substract has differences in water holding capacity and aeration. Therefore, it is very important to determine the amount of water applied to cucumber grown in various substrates based on the estimated cucumber evapotranspiration requirements (ETc) that can enhance cucumber growth and development, improve yields but reduce costs. The experiment was carried out in the experiment site of Nong Lam University Ho Chi Minh City from June to August 2016 with four irrigation levels and four substrates that were arranged in a split-plot design with three replications. Four irrigation levels (60, 80,100 and $120 \%$ of ETc) were allocated to main plots, and four substrates including $100 \%$ coconut coir, $50 \%$ coconut coir $+50 \%$ peanut shells, $50 \%$ coconut coir $+50 \%$ sand, and $50 \%$ sawdust + $50 \%$ sand were allocated to subplots. Growth attributes and yield components of cucumber were determined. The results showed that cucumber grown on the substrate $50 \%$ coconut coir $+50 \%$ sand and irrigated by $120 \%$ ETc (corresponding $226 \mathrm{~mL} /$ plant/day at 3 weeks after planting - WAP, $280 \mathrm{~mL} /$ plant/day at $3-5 \mathrm{WAP}$ and 236 $\mathrm{mL} /$ plant/day at late $5 \mathrm{WAP}$ ) performed the highest absolute yield and commercial yield $\left(7.50 \mathrm{~kg} / \mathrm{m}^{2}\right.$ and $7.48 \mathrm{~kg} / \mathrm{m}^{2}$, respectively), and had the highest profit $\left(71,738,746 \mathrm{VND} 1,000 / \mathrm{m}^{2}\right.$, and the profit ratio was 1.77 ).
\end{abstract}

Cited as: Pham, N. H., Huynh, H. T., \& Nguyen, D. T. (2018). Determination of the amount of irrigation water for cucumber (Cucumis sativus L.) grown on four types of substrate. The Journal of Agriculture and Development 17(5), 20-28. 


\title{
Xác định lượng nước tưởi phù hợp cho cây dưa leo (Cucumis sativus L.) trồng trên bốn loại giá thể
}

\author{
Phạm Hữu Nguyên*, Huỳnh Thanh Hùng \& Nguyễn Tiến Dũng \\ Khoa Nông Học, Trường Đại Học Nông Lâm TP. Hồ Chí Minh, TP. Hồ Chí Minh
}

\section{THÔNG TIN BÀI BÁO}

Bài báo tổng quan

Ngày nhận: 31/01/2018

Ngày chỉnh sửa: $07 / 05 / 2018$

Ngày chấp nhận: 10/05/2018

\section{Từ khóa}

Bốc thoát hơi nước

Canh tác không đất

Dưa leo

Giá thể

Lượng nước tưới

*Tác giả liên hệ

Phạm Hữu Nguyên

Email: phnguyen@hcmuaf.edu.vn

\section{TÓM TẮT}

Có rất nhiều giá thể được sử dụng trong canh tác không đất, nhưng mỗi loại giá thể có khả năng giữ nước và không khí khác nhau. Do vậy, việc nghiên cứu xác định lượng nước tưới dựa trên bốc thoát hơi nước $(\mathrm{ETc})$ của cây phù hợp cho cây dưa leo trồng trên từng loại giá thể trong điều kiện môi trường nhất định để cây sinh trưởng phát triển tốt, đạt năng suất cao và giảm chi phí đầu tư trong quá trình canh tác là điều cần thiết. Thí nghiệm đã được tiến hành tại Trại thực nghiệm Trường Đại học Nông Lâm thành phố Hồ Chí Minh từ 06/2016 đến tháng 8/2016 với bốn lượng nước tưới và bốn loại giá thể, được bố trí theo kiểu lô phụ (Split - plot design) với ba lần lặp lại; Yếu tố lô chính là 4 lượng nước tưới $(\mathrm{A})$ được tính theo bốc thoát hơi cây trồng (ETc): Tưới $60 \% \mathrm{ETc}$, tưới $80 \% \mathrm{ETc}$, tưới $100 \% \mathrm{ETc}$ và tưới $120 \%$ ETc; Yếu tố lô phụ là 4 công thức giá thể (B) được phối trộn theo thể tích: $100 \%$ xơ dừa $(\mathrm{XD}), 50 \% \mathrm{XD}+50 \%$ vỏ dậu phộng $(\mathrm{VDP}), 50 \% \mathrm{XD}+50 \%$ cát và $50 \%$ mùn cưa $(\mathrm{MC})+50 \%$ cát. Theo dõi các chỉ tiêu về sinh trưởng, phát triển và năng suất của cây. Kết quả thí nghiệm cho thấy dưa leo được trồng trong giá thể $50 \% \mathrm{XD}$ + 50\% cát và tưới với lượng nước tưới $120 \%$ ETc (226 mL/cây/ngày giai đoạn 3 tuần sau trồng, $280 \mathrm{~mL} /$ cây/ngày giai đoạn $3-5$ tuần sau trồng, $236 \mathrm{~mL} /$ cây/ngày giai đoạn sau 5 tuần trồng) có năng suất thực thu và năng suất thương phẩm cao nhất $\left(7,50 \mathrm{~kg} / \mathrm{m}^{2}\right.$ và $\left.7,48 \mathrm{~kg} / \mathrm{m}^{2}\right)$ và đạt hiệu quả kinh tế cao nhất (71.738.746 đồng/1.000 $\mathrm{m}^{2}$, tỷ suất lợi nhuận đạt 1,77$)$.

\section{1. Đặt Vấn Đề}

Trong điều kiện canh tác không đất đối với cây rau nói chung và dưa leo nói riêng, lượng nước tưới và thoát nước là hai tiêu chí cần kiểm soát. Canh tác không đất trong điều kiện nhà lưới, tính toán lượng nước cần tưới không chỉ đáp ứng nhu cầu nước cần cho cây sinh trưởng và phát triển mà còn góp phần điều chỉnh điều kiện tiểu khí hậu xung quanh cây trồng (Schröder \& Lieth, 2002). Song song với lượng nước tưới, vật liệu sử dụng làm giá thể góp phần không nhỏ vào sự thành công của hệ thống canh tác không đất. Các loại vật liệu vô cơ và hữu cơ đều được sử dụng làm giá thể trồng. Đối với vật liệu vô cơ, đá núi lửa (perlite), bông khoáng (rockwool) và cát là những vật liệu được sử dụng phổ biến (Islam \& ctv., 2002; Olle \& ctv., 2012). Trong khi đó với vật liệu hữu cơ, các loại vật liệu như xơ dừa, tro trấu, compost và than bùn được sử dụng rộng rãi (Böhme \& ctv., 2001; Olle \& ctv., 2012). Tại Việt Nam, các giá thể hữu cơ được dùng nhiều hơn là các giá thể vô cơ do giá thành và tính sẵn có của vật liệu. Các vật liệu như xơ dừa, tro trấu và vỏ đậu phộng thường được sử dụng dùng làm giá thể trồng cho nhiều loại cây trồng khác nhau (Nguyen \& Nguyen, 2009; Tran \& ctv., 2009).

Trong việc canh tác không đất áp dụng cho cây dưa leo, việc sử dụng các loại vật liệu sẵn có, dễ tìm, giá thành thấp như mụn xơ dừa, vỏ đậu phộng, cát nhằm giảm chi phí đầu tư đầu luôn là ưu tiên hàng đầu. Tuy nhiên, với các vật liệu trồng khác nhau, khả năng giữ nước và cung cấp nước cho cây sử dụng sẽ khác nhau. Vì vậy, 
việc tính toán lượng nước tưới cho cây dưa leo trong điều kiện canh tác không đất dựa vào các loại giá thể khác nhau và quá trình bốc thoát hơi nước của cây là cần thiết để xác định được lượng nước cần cung cấp tương ứng cho loại giá thể nhất định, đồng thời đảm bảo được hiệu quả kinh tế của quy trình canh tác cây dưa leo canh tác không đất.

\section{Vật Liệu và Phương Pháp Nghiên Cứu}

- Giống: Thí nghiệm sử dụng giống dưa leo $\mathrm{F}_{1}$ Galaxy102. Giống có một số đặc tính (theo mô tả của nhà sản xuất): thân to, nhiều nhánh, trái suôn, dài từ 17 - $18 \mathrm{~cm}$, trái màu xanh, ruột nhỏ, ăn giòn, ngọt, thu hoạch sau 34 - 35 ngày sau gieo, thời gian thu hoạch kéo dài đến 35 ngày. Kháng bệnh tốt, có khả năng đậu trái tốt trong điều kiện nhiệt độ cao, năng suất trung bình từ 4,0 - 4,5 kg/cây, khoảng 6 - 7 tấn $/ 1.000 \mathrm{~m}^{2}$.

- Điều kiện thí nghiệm:

Thí nghiệm được tiến hành trong điều kiện nhà lưới thuộc Khoa Nông học, Trường Đại học Nông Lâm Tp. Hồ Chí Minh. Nhiệt độ trong nhà lưới được điều chỉnh ở mức $25 \pm 5^{0} \mathrm{C}$.

Hệ thống nhỏ giọt với nồng độ các chất dinh dưỡng được điều chỉnh khác nhau cho các giai đoạn sinh trưởng phát triển của cây dưa leo (Bảng 1). Công thức dinh dưỡng được sử dụng trong thí nghiệm được cải tiến từ công thức dinh dưỡng của $\mathrm{FAO}$ và kết quả nghiên cứu của Tran (2015), cụ thể: Giai đoạn < 21 ngày sau trồng: cung cấp tăng thêm $5 \%$ N, 21 - 35 ngày sau trồng: tăng thêm $5 \% \mathrm{P}$ và $>35$ ngày sau trồng dến hết vụ (Giai đoạn ra hoa kết quả): cung cấp thêm $5 \%$ $\mathrm{N}+5 \% \mathrm{~K}$.

Các nguyên tố trung vi lượng sử dụng từ đầu đến cuối vụ với nồng độ: Ca: 182,0ppm; Mg: 99,6 ppm; Fe: 1,6 ppm; Cu: 0,03 ppm; Mn: 0,6 ppm; Zn: 2,0 ppm; B: 0,4 ppm; Mo: 0,7 ppm. EC được điều chỉnh ở mức $1,7-2,5 \mathrm{mS} / \mathrm{cm}$ và $\mathrm{pH}$ được giữ ổn định ở mức 5,5 - 6,0 để đảm bảo dung dịch dinh dưỡng luôn ổn định.

- Bố trí thí nghiệm:

Thí nghiệm gồm 16 nghiệm thức (NT) được bố trí theo kiểu lô phụ (split-plot design) (Gomez \& Gomez, 1984), hai yếu tố và ba lần lặp lại:

Yếu tố lô chính $(\mathrm{A})$ : Bốn lượng nước tưới được tính toán dựa trên lượng bốc thoát hơi nước (ETc) của cây dưa leo gồm: $120 \%$ ETc; $100 \%$ ETc; $80 \%$ ETc; $60 \%$ ETc (Bảng 2).
Yếu tố lô phụ (B): Sử dụng bốn công thức giá thể, các giá thể được phối trộn theo thể tích: $100 \%$ xơ dừa $(\mathrm{XD}) ; 50 \% \mathrm{XD}+50 \%$ vỏ đậu phộng (VĐP); $50 \% \mathrm{XD}+50 \%$ cát $(\mathrm{C})$ và $50 \%$ mùn cưa (MC) $+50 \%$ cát.

Tổng số bầu giá thể: 48 ô $\times 10$ cây/ô trồng $\times 1$ cây/bầu giá thể $=480$ bầu giá thể có kích thước $25 \mathrm{~cm} \times 25 \mathrm{~cm}$. Diện tích ô: $1,5 \mathrm{~m} \times 1 \mathrm{~m}=1,5$ $\mathrm{m}^{2}$. Diện tích thí nghiệm: $48 \times 1,5 \mathrm{~m}^{2}=72 \mathrm{~m}^{2}$. Tổng diện tích: $80 \mathrm{~m}^{2}$. Khoảng cách và mật độ trồng: cây cách cây $30 \mathrm{~cm}$, hàng cách hàng $50 \mathrm{~cm}$, tương đương mật độ trồng 66.667 cây/ha.

- Thu thập và phân tích số liệu: Mỗi ô cơ sở chọn 5 cây để thu thập số liệu liên quan đến các chỉ tiêu sinh trưởng (chiều dài thân chính, số cành cấp 1 và số lá) được thu thập ở 47 ngày sau trồng (NST). Các giai đoạn phát dục (ngày ra hoa, ngày ở hoa cái đầu tiên, ngày ra quả và ngày thu hoạch) và năng suất của các nghiệm thức được xác định nhằm đánh giá tác động giữa các lượng nước tưới và các loại giá thể trồng. Phân tích phương sai (ANOVA) và trắc nghiệm phân hạng bằng phần mềm SAS phiên bản 9.1.

\section{Kết Quả và Thảo Luận}

\subsection{Kết quả}

3.1.1. Ảnh hưởng của bốn lượng nước tưới và loại giá thể đến sự sinh trưởng cây dưa leo trồng vụ Hè Thu 2016 tại Thủ Đức, thành phố Hồ Chí Minh

Xét ảnh hưởng của các lượng nước tưới đến chiều cao cây, số liệu trình bày ở Bảng 3 cho thấy rằng, khi tăng lượng nước tưới từ $60 \% \mathrm{ETc}$ lên $120 \%$ ETc thì chiều cao cây của cây dưa leo tăng dần. Sự khác biệt về chiều cao cây khi được tưới bằng các lượng nước tưới khác nhau rất có ý nghĩa trong thống kê, trong đó cây được tưới bằng lượng nước tưới $120 \%$ ETc đạt chiều cao cây trung bình cao nhất (214,6 cm/cây), khác biệt không có ý nghĩa so với cây được tưới bằng lượng nước tưới $100 \%$ ETc $(186,6$ cm/cây) và khác biệt rất có ý nghĩa so với cây được tưới bằng 2 lượng nước tưới còn lại. Chiều cao cây khi trồng ở bốn công thức giá thể khác biệt không có ý nghĩa trong thống kê và biến động trong khoảng 162,6 cm/cây (giá thể sử dụng $50 \% \mathrm{MC}+50 \%$ cát) đến $180,9 \mathrm{~cm} /$ cây (giá thể sử dụng $100 \% \mathrm{XD}$ ). Sự tương tác giữa bốn lượng nước tưới và bốn công thức giá thể trồng đến chiều cao cây dưa leo khác biệt không có ý nghĩa thống kê. 
Bảng 1. Yếu tố dinh dưỡng điều chỉnh theo giai đoạn sinh trưởng của cây dưa leo ${ }^{1}$

\begin{tabular}{cccc}
\hline Nồng độ $(\mathrm{ppm})$ & \multicolumn{3}{c}{ Giai đoạn sinh trưởng } \\
\cline { 2 - 4 } & $<21$ ngày sau trồng & $21-35$ ngày sau trồng & 35 ngày sau trồng \\
\hline $\mathrm{N}$ & 174,6 & 166,3 & 174,6 \\
$\mathrm{P}$ & 13,3 & 14,0 & 13,3 \\
$\mathrm{~K}$ & 230,0 & 230,0 & 241,5 \\
\hline
\end{tabular}

${ }^{1}$ FAO, 1992; Tran, 2015.

Bảng 2. Liều lượng dung dịch dinh dưỡng ( $\mathrm{mL} / \mathrm{cây} / \mathrm{ngày})$ và thời gian tưới (phút/cây/ngày) cho cây dưa leo ở các giai đoạn sinh trưởng theo thời gian trồng

\begin{tabular}{cccc}
\hline Lượng nước tưới & \multicolumn{3}{c}{ Giai đoạn sinh trưởng } \\
\cline { 2 - 4 } & 3 tuần sau trồng & 3 - 5 tuần sau trồng & Sau 5 tuần \\
\hline $120 \%$ & ETc 226 (11) & $280(14)$ & $236(12)$ \\
$100 \%$ & ETc 183 (9) & $233(12)$ & $197(10)$ \\
$80 \%$ & ETc 146 (7) & $186(9)$ & $158(8)$ \\
$60 \%$ & ETc 110 (5) & $140(7)$ & $118(6)$ \\
\hline
\end{tabular}

${ }^{1}$ Số trong ngoặc đơn (): Thời gian tưới (phút/cây/ngày). Thời điểm tưới nước cho dưa leo: 8 giờ 00 sáng.

Kết quả theo dõi số lá trên cây ở các nghiệm thức (Bảng 3) cho thấy có sự tác động của lượng nước tưới đến số lá của cây dưa leo. Tương tự chiều cao cây, số lá trung bình trên cây tăng dần khi tăng lượng nước tưới từ $60 \%$ ETc lên $120 \%$ ETc. Tính trung bình cho cả bốn công thức tưới, kết quả thống kê cho thấy số lá đạt cao nhất khi áp dụng lượng nước tưới 120\% ETc (31,4 lá/cây), khác biệt không có ý nghĩa thống kê so với số lá ở lượng nước tưới tưới 100\% ETc (28,8 lá/cây); số lá/cây ở hai lượng nước tưới này khác biệt có ý nghĩa so với lượng nước tưới $80 \%$ ETc $(24,2$ lá/cây) và $60 \%$ ETc (23,9 lá/cây). Kết quả phân tích số lá/cây trung bình tính cho từng loại giá thể cho thấy không có sự khác biệt trong thống kê và số lá/cây ở bốn công thức giá thể dao động trong khoảng 26,5 lá/cây (giá thể $50 \% \mathrm{MC}+$ $50 \%$ cát) đến 28,1 lá/cây (giá thể $50 \% \mathrm{XD}+50 \%$ VĐP). Sự tương tác giữa bốn lượng nước tưới và bốn công thức giá thể trồng đến số lá của cây dưa leo khác biệt không có ý nghĩa thống kê và biến động từ 21,4 lá/cây (cây được tưới $60 \%$ ETc và trồng trong giá thể $100 \% \mathrm{XD}$ ) đến 32,8 lá/cây (cây được tưới $120 \%$ ETc và trồng trong giá thể $50 \% \mathrm{XD}+50 \% \mathrm{VĐP})$.

Tổng số nhánh cấp 1 giữa các cây được tưới theo lượng nước tưới khác nhau khác biệt rất có ý nghĩa trong thống kê, số nhánh biến động trong khoảng 1,8 - 3,0 nhánh/cây, cá biệt các cây dưa leo khi được tưới theo lượng nước $60 \%$ ETc tại thời điểm 47 NST hầu như không phân nhánh cấp 1. Khi tăng lượng nước tưới từ $60 \%$ ETc lên $120 \%$ $\mathrm{ETc}$, số nhánh cấp 1 trung bình trên cây tăng dần trong đó số nhánh nhiều nhất ở cây được tưới theo lượng nước tưới 120\% ETc (3,0 nhánh/cây), khác biệt có ý nghĩa so với cây được tưới bằng 3 lượng nước tưới còn lại. Sự khác biệt về tổng số nhánh trên cây giữa các cây được trồng trong các giá thể khác nhau khác biệt có ý nghĩa trong thống kê, số nhánh biến động từ 1,8 - 2,5 nhánh/cây, trong đó số nhánh cao nhất là ở cây được trồng trong giá thể 100\% XD (2,5 nhánh/cây), khác biệt có ý nghĩa so với cây được trồng trong giá thể $50 \%$ $\mathrm{MC}+50 \%$ cát và khác biệt không có ý nghĩa so với 2 giá thể còn lại. Sự tương tác giữa lượng nước tưới và giá thể trồng tạo ra sự khác biệt rất có ý nghĩa thống kê giữa tổng số nhánh của cây dưa leo. Cây dưa leo trồng trong giá thể $100 \%$ XD, $50 \% \mathrm{XD}+50 \%$ cát và trồng trong giá thể $50 \%$ $\mathrm{XD}+50 \% \mathrm{VĐP}$ đồng thời được tưới với lượng nước tưới 120\% ETc có số nhánh khác biệt không có ý nghĩa so với cây dưa leo trồng trong giá thể $50 \% \mathrm{XD}+50 \%$ cát đồng thời tưới với $100 \% \mathrm{ETc}$, nhưng khác biệt rất có ý nghĩa so với các lượng nước tưới và giá thể trồng còn lại.

\subsection{2. Ảnh hưởng của bốn lượng nước tưới và giá thể đến khả năng phát dục của cây dưa leo trồng vụ Hè Thu 2016 tại Thủ Đức, Thành phố Hồ Chí Minh}

Xét chỉ tiêu ngày ra hoa trình bày ở Hình $1 \mathrm{~A}$ : Cây dưa leo trồng trên giá thể $100 \%$ XD được tưới ở lượng nước tưới 120\% ETc có thời gian ra nụ của cây muộn nhất là $28 \mathrm{NST}$, thời gian này kéo dài hơn từ 7 tới 10 ngày so với các nghiệm 
Bảng 3. Ảnh hưởng của bốn chế độ tưới và bốn loại giá thể đến sinh trưởng của cây dưa leo tại thời điểm 47 ngày sau trồng

\begin{tabular}{|c|c|c|c|c|c|c|}
\hline \multirow{2}{*}{ Chỉ tiêu } & \multirow{2}{*}{ Lượng nước tưới (A) } & \multicolumn{4}{|c|}{ Giá thể $(\mathrm{B})$} & \multirow{2}{*}{$\mathrm{TB}_{\mathrm{A}}$} \\
\hline & & $100 \% \mathrm{XD}$ & $\begin{array}{c}50 \% \text { XD } \\
+ \\
50 \% \text { VĐP }\end{array}$ & $\begin{array}{c}50 \% \mathrm{XD} \\
+ \\
50 \% \mathrm{C}\end{array}$ & $\begin{array}{c}50 \% \mathrm{MC} \\
+ \\
50 \% \mathrm{C}\end{array}$ & \\
\hline \multirow{6}{*}{$\begin{array}{l}\text { Chiều cao cây } \\
\text { (cm/cây) }\end{array}$} & $120 \%$ ETc & 224,5 & 224,2 & 201,2 & 208,5 & $214,6^{\mathrm{a}}$ \\
\hline & $100 \%$ ETc & 193,2 & 189,7 & 180,2 & 183,4 & $186,6^{\mathrm{a}}$ \\
\hline & $80 \%$ ETc & 148,9 & 147,2 & 141,3 & 128,9 & $141,6^{\mathrm{b}}$ \\
\hline & $60 \% \mathrm{ETc}$ & 157,0 & 144,2 & 142,1 & 129,6 & $143,2^{\mathrm{b}}$ \\
\hline & $\mathrm{TB}_{\mathrm{B}}$ & 180,9 & 176,3 & 166,2 & 162,6 & \\
\hline & \multicolumn{5}{|c|}{$\mathrm{CV}(\%)=12,83 ; \mathrm{F}_{\mathrm{A}}=23,82^{* *} ; \mathrm{F}_{\mathrm{B}}=1,8^{\mathrm{ns}} ; \mathrm{F}_{\mathrm{A}}{ }^{*} \mathrm{~B}=0,18^{\mathrm{ns}}$} & \\
\hline \multirow{7}{*}{$\begin{array}{c}\text { Số lá } \\
\text { (lá/cây) }\end{array}$} & $120 \%$ ETc & 31,5 & 32,8 & 31,1 & 30,1 & $31,4^{\mathrm{a}}$ \\
\hline & $100 \%$ ETc & 28,2 & 29,5 & 29,1 & 28,5 & $28,8^{\mathrm{a}}$ \\
\hline & $80 \% \mathrm{ETc}$ & 24,5 & 25,4 & 23,1 & 23,8 & $24,2^{\mathrm{b}}$ \\
\hline & $80 \% \mathrm{ETc}$ & 24,5 & 25,4 & 23,1 & 23,8 & $24,2^{\mathrm{b}}$ \\
\hline & $60 \% \mathrm{ETc}$ & 24,1 & 24,6 & 23,4 & 23,4 & $23,9^{\mathrm{b}}$ \\
\hline & $\mathrm{TB}_{\mathrm{B}}$ & 27,1 & 28,1 & 26,7 & 26,5 & \\
\hline & \multicolumn{5}{|c|}{$\mathrm{CV}(\%)=5,79 ; \mathrm{F}_{\mathrm{A}}=33,85^{* *} ; \mathrm{F}_{\mathrm{B}}=2,58^{\mathrm{ns}} ; \mathrm{F}_{\mathrm{A} * \mathrm{~B}}=0,32^{\mathrm{ns}}$} & \\
\hline \multirow{6}{*}{$\begin{array}{l}\text { Số nhánh cấp } 1 \\
\text { (nhánh/cây) }\end{array}$} & $120 \%$ ETc & $3,5^{\mathrm{a}}$ & $3,3^{\mathrm{ab}}$ & $3,5^{\mathrm{a}}$ & $1,5^{\mathrm{c}}$ & $3,0^{\mathrm{a}}$ \\
\hline & $100 \% \mathrm{ETc}$ & $2,3^{\mathrm{c}}$ & $2,4^{\mathrm{bc}}$ & $2,6^{\mathrm{abc}}$ & $1,9^{\mathrm{c}}$ & $2,3^{\mathrm{b}}$ \\
\hline & $80 \% \mathrm{ETc}$ & $1,7^{\mathrm{c}}$ & $1,8^{\mathrm{c}}$ & $1,9^{\mathrm{c}}$ & $2,0^{\mathrm{c}}$ & $1,9^{\mathrm{b}}$ \\
\hline & $60 \% \mathrm{ETc}$ & - & $1,8^{\mathrm{c}}$ & $1,7^{\mathrm{c}}$ & $1,8^{\mathrm{c}}$ & $1,8^{\mathrm{b}}$ \\
\hline & $\mathrm{TB}_{\mathrm{B}}$ & $2,5^{\mathrm{a}}$ & $2,3^{\mathrm{a}}$ & $2,4^{\mathrm{a}}$ & $1,8^{\mathrm{b}}$ & \\
\hline & \multicolumn{5}{|c|}{$\mathrm{CV}(\%)=18,38 ; \mathrm{F}_{\mathrm{A}}=18,10^{* *} ; \mathrm{F}_{\mathrm{B}}=4,82^{*} ; \mathrm{F}_{\mathrm{A} * \mathrm{~B}}=4,20^{* *}$} & \\
\hline
\end{tabular}

$\overline{\mathrm{a}-\mathrm{c}}$ Trong cùng một hàng hoặc cột, các chữ số có cùng ký tự theo sau khác biệt không có ý nghĩa thống kê. ns: Khác biệt không có ý nghĩa về mặt thống kê $(P>0,05)$; * khác biệt có ý nghĩa về mặt thống kê $(P<0,05)$; **: khác biệt rất có ý nghĩa về mặt thống kê $(P \leq 0,01)$.

thức (NT) còn lại. Ngược lại, cây có thời gian ra nụ sớm nhất tại thời điểm 18 NST là cây dưa leo ở NT kết hợp lượng nước tưới $120 \% \mathrm{ETc}$ và loại giá thể $50 \% \mathrm{XD}+50 \%$ cát. Thời gian có hoa đầu tiên của các NT còn lại dao động trong khoảng 19 đến 23 NST.

Về chỉ tiêu ngày có hoa cái đầu tiên nở: Hình 1B cho thấy NT tưới $120 \%$ ETc trên loại giá thể $50 \%$ XD $+50 \%$ cát có hoa cái nở sớm nhất ở thời điểm 24 NST. Ngược lại, NT tưới $60 \%$ ETc trên giá thể $50 \% \mathrm{MC}+50 \%$ cát có thời gian hoa cái đầu tiên nở kéo dài đến $33 \mathrm{NST}$. Thời gian nở hoa cái đầu tiên của các NT còn lại dao động trong khoảng 26 đến 32 NST.

Ngày đậu quả được xác định sau khi hoa cái đã thụ phấn và quả đã được định hình. Số liệu theo dõi trình bày ở Hình $1 \mathrm{C}$ cho thấy thời gian đậu quả ở loại giá thể $50 \% \mathrm{MC}+50 \%$ cát là muộn nhất ở cả 4 công thức tưới, trong đó thời gian đậu quả muộn nhất đối với loại giá thể này cùng với lượng nước tưới $60 \%$ ETc (36 NST). Thời gian đậu quả sớm nhất là ở NT kết hợp giữa lượng nước tưới $120 \%$ ETc và loại giá thể $50 \%$ XD +
$50 \%$ cát (27 NST). Các NT còn lại biến động trong khoảng 29 đến 35 NST.

Ngày bắt đầu thu hoạch được xác định khi quả đủ tiêu chuẩn thương phẩm (quả đủ độ cứng, gai nhẵn, vỏ bóng). Hình $1 \mathrm{D}$ cho thấy thời gian bắt đầu thu hoạch quả ở các NT dao động trong khoảng 32 NST (NT tưới 120\% ETc trên giá thể $100 \%$ XD) đến 40 NST (NT tưới $60 \%$ ETc trên giá thể $50 \% \mathrm{MC}+50 \%$ cát). Các NT còn lại dao động từ 33 đến 39 NST.

\subsection{3. Ảnh hưởng của bốn lượng nước tưới và giá thể đến năng suất quả dưa leo trồng vụ Hè Thu 2016 tại Thủ Đức, Thành phố Hồ Chí Minh}

Kết quả Bảng 4 cho thấy có sự khác biệt rất có ý nghĩa trong thống kê về chỉ tiêu năng suất lý thuyết (NSLT, $\mathrm{kg} / \mathrm{m}^{2}$ ) giữa các lượng nước tưới. Trong đó, cây dưa leo được tưới với lượng nước tưới $120 \%$ ETc dạt NSLT trung bình cao nhất $\left(7,87 \mathrm{~kg} / \mathrm{m}^{2}\right)$ khác biệt rất có ý nghĩa so với 3 nghiệm thức sử dụng lượng nước tưới còn lại. NSLT trung bình của cây dưa leo khi được tưới ở 

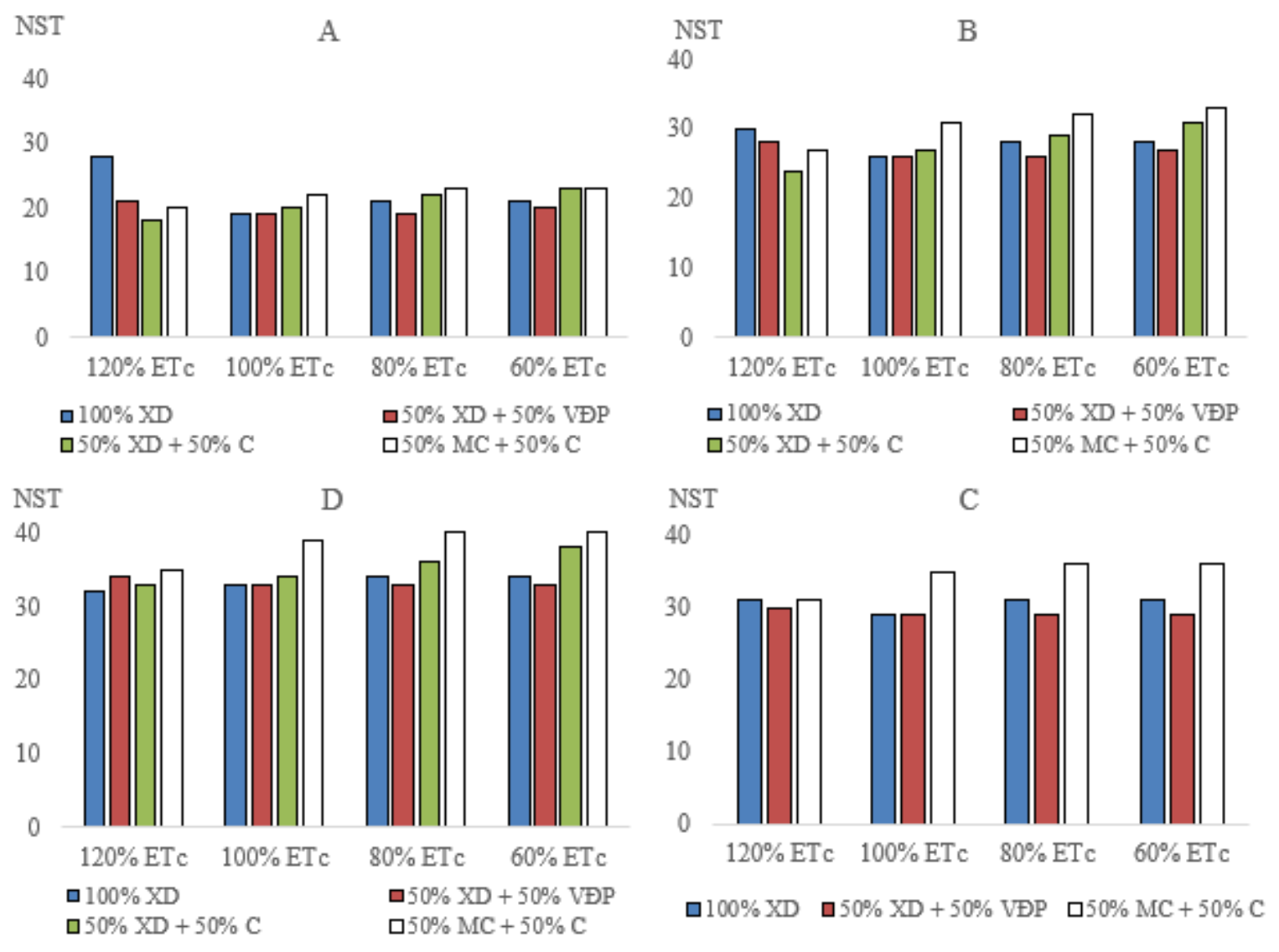

Hình 1. Tác động của 4 lượng nước tưới và loại giá thể trồng đến ngày ra hoa $(\mathrm{A})$, ngày nở hoa cái đầu tiên $(\mathrm{B})$, ngày đậu quả $(\mathrm{C})$ và ngày bắt đầu thu hoạch quả $(\mathrm{D})$ của dưa leo.

hai lượng $80 \%$ ETc và $60 \%$ ETc khác biệt không có ý nghĩa thống kê và đạt lần lượt là $3,58 \mathrm{~kg} / \mathrm{m}^{2}$ và $3,61 \mathrm{~kg} / \mathrm{m}^{2}$. Sự khác biệt về NSLT trung bình của cây dưa leo trồng trên ba công thức giá thể $50 \% \mathrm{XD}+50 \% \operatorname{VĐP}\left(5,50 \mathrm{~kg} / \mathrm{m}^{2}\right)$, giá thể $50 \%$ $\mathrm{XD}+50 \%$ cát $(5,49 \mathrm{~kg} / \mathrm{m} 2)$ và giá thể $100 \%$ XD $\left(5,31 \mathrm{~kg} / \mathrm{m}^{2}\right)$ không có nghĩa trong thống kê nhưng khác biệt ở có nghĩa so với khi trồng trên giá thể $50 \% \mathrm{MC}+50 \%$ cát $\left(4,40 \mathrm{~kg} / \mathrm{m}^{2}\right)$. Xét tương tác giữa lượng nước tưới và loại giá thể trồng, kết quả ghi nhận lượng nước tưới $120 \%$ ETc trên nền giá thể $50 \% \mathrm{XD}+50 \%$ cát đạt năng suất cao nhất $\left(8,87 \mathrm{~kg} / \mathrm{m}^{2}\right)$, thấp nhất là NT áp dụng lượng nước tưới $60 \%$ ETc trên giá thể $50 \% \mathrm{MC}+50 \%$ cát $\left(3,25 \mathrm{~kg} / \mathrm{m}^{2}\right)$. Tuy nhiên, NSLT giữa các nghiệm thức khác biệt không có ý nghĩa thống kê.

Kết quả theo dõi năng suất thực tế (NSTT, $\mathrm{kg} / \mathrm{m}^{2}$ ) trình bày ở Bảng 4 cho thấy có sự khác biệt rất có ý nghĩa về mặt thống kê giữa các lượng nước tưới và cả loại giá thể trồng. Cụ thể đối với lượng nước tưới áp dụng $120 \%$ ETc cho NSTT trung bình tính trên bốn loại giá thể khác nhau là cao nhất $\left(6,67 \mathrm{~kg} / \mathrm{m}^{2}\right)$ và khác biệt rất có nghĩa so với NSTT trung bình ở lượng nước tưới $60 \%$ ETc $\left(2,39 \mathrm{~kg} / \mathrm{m}^{2}\right)$. NSTT trung bình ở lượng nước tưới $80 \%$ ETc $\left(2,78 \mathrm{~kg} / \mathrm{m}^{2}\right)$ khác biệt không có nghĩa thống kê so với NSTT trung bình ở lượng nước tưới $60 \% \mathrm{ETc}$. Trong khi NSTT trung bình ở lượng nước tưới 100\% ETc $\left(4,49 \mathrm{~kg} / \mathrm{m}^{2}\right)$ khác biệt không có nghĩa thống kê so với NSTT trung bình ở lượng nước tưới $80 \%$ ETc, nhưng khác biệt rất có nghĩa so NSTT ở lượng nước tưới $60 \%$ ETc. Xét tương tác giữa lượng nước tưới và loại giá thể cho thấy NT được tưới lượng nước tưới $120 \%$ ETc trên giá thể $50 \%$ XD $+50 \%$ cát cho NSTT cao nhất $\left(7,50 \mathrm{~kg} / \mathrm{m}^{2}\right)$, trong khi NT kết hợp giữa lượng nước tưới $60 \%$ ETc trên loại giá thể $50 \% \mathrm{MC}+50 \%$ cát có NSTT thấp nhất $(1,89$ $\left.\mathrm{kg} / \mathrm{m}^{2}\right)$. Các NT còn lại dao động trong khoảng 


\section{$2,23 \mathrm{~kg} / \mathrm{m}^{2}$ đến $7,35 \mathrm{~kg} / \mathrm{m}^{2}$.}

Năng suất thương phẩm (NSTP, $\left.\mathrm{kg} / \mathrm{m}^{2}\right)$ : Năng suất thương phẩm của cây dưa leo được tưới bằng các lượng nước tưới khác nhau khác biệt rất có ý nghĩa về mặt thống kê, cây dưa leo đạt NSTP cao nhất là ở lượng nước tưới $120 \%$ ETc với 6,58 $\mathrm{kg} / \mathrm{m}^{2}$, khác biệt rất có ý nghĩa so với cây được tưới bằng 3 lượng nước tưới còn lại. Theo Nguyen (2016), giống dưa leo Galaxy102 khi trồng trong giá thể $100 \% \mathrm{XD}$ với mật độ 8.333 cây $/ 1.000 \mathrm{~m}^{2}$ trong điều kiện nhà lưới tại thành phố Hồ Chí Minh có NSTP là $9,83 \mathrm{~kg} / \mathrm{m}^{2}$. Sự khác biệt về NSTP giữa các cây trồng trong các giá thể khác nhau khác biệt rất có ý nghĩa trong thống kê, NSTP biến động từ $2,86-4,33 \mathrm{~kg} / \mathrm{m} 2$, cao nhất khi trồng trong giá thể $100 \%$ XD $\left(4,33 \mathrm{~kg} / \mathrm{m}^{2}\right)$, khác biệt rất có ý nghĩa so với cây trồng trong giá thể $50 \% \mathrm{MC}+50 \%$ cát và khác biệt không có ý nghĩa so với 2 giá thể còn lại. Sự tương tác giữa các lượng nước tưới và giá thể trồng đến NSTP khác biệt không có ý nghĩa trong thống kê.

\subsection{4. Ảnh hưởng của bốn lượng nước tưới và giá thể đến hiệu quả kinh tế cây dưa leo trồng vụ Hè Thu 2016 tại Thủ Đức, thành phố Hồ Chí Minh}

Qua Bảng 5 cho thấy trong cùng một công thức giá thể, khi lượng nước tưới càng giảm thì lợi nhuận cũng giảm theo. Cây dưa leo được tưới lượng nước tưới $120 \% \mathrm{ETc}$, trồng trong giá thể $50 \%$ XD + 50\% cát đạt lợi nhuận cao nhất là 71.738 .746 đồng/ $1.000 \mathrm{~m}^{2} / \mathrm{vụ}$; kế đến là dưa leo được tưới với lượng nước tưới $120 \% \mathrm{ETc}$, trồng trong giá thể $100 \%$ XD (57.588.687 đồng/1.000 $\mathrm{m}^{2} / \mathrm{vu}$ ). Cây dưa leo được tưới với lượng nước tưới $80 \%$ ETc và lượng nước tưới $60 \%$ ETc vì có lượng nước tưới thấp nên cây dưa leo không thể phát triển tốt và cho năng suất cao. Bên cạnh đó, những cây dưa leo được tưới với lượng nước tưới này còn cho quả có vị đắng không phù hợp với nhu cầu thị hiếu của người tiêu dùng.

\subsection{Thảo Luận}

Dưa leo được xếp vào loại rau ăn quả (FAO, 2005), vì vậy, việc tác động các biện pháp canh tác giúp cây tăng trưởng mạnh ở các chỉ tiêu sinh trưởng sinh dưỡng là cần thiết để cây sớm ra hoa, đậu quả. Kết quả thí nghiệm với các lượng nước tưới khác nhau, trên các loại giá thể khác nhau cho thấy khi tăng lượng nước tưới từ $60 \% \mathrm{ETc}$ lên $120 \%$ ETc thì chiều cao, số lá, số cành cấp 1 ,
NSLT và NSTT có chiều hướng tăng dần. Trong khi đó, ở các lượng nước tưới với lượng nước thấp hơn 100\% ETc chưa đáp ứng đủ nhu cầu nước cho cây sinh trưởng. Khi lượng nước tưới không đáp ứng nhu cầu của cây thì cây có khuynh hướng phát triển thiên về sinh trưởng sinh thực (Resh, 2012). Kết quả theo dõi ảnh hưởng của bốn lượng nước tưới đối với quá trình phát dục của cây dưa leo trồng trên bốn loại giá thể khác nhau lại không tuân theo quy luật này. Nguyên nhân là do khả năng giữ nước của các loại giá thể khác nhau, nên khả năng cung ứng nước cho cây trồng khác nhau.

Theo nghiên cứu của Pham (2015), đối với cây dưa leo ở giai đoạn 3 tuần sau trồng, lượng nước trung bình cần đáp ứng cho cây là 1.000 mL/ngày (200mL/lần/cây ×tưới 5 lần/ngày); sau đó tăng lên $1.200 \mathrm{~mL} /$ cây/ngày $(200 \mathrm{~mL} /$ lần/cây x 6 lần/ngày). Tuy nhiên, Grewal \& ctv. (2011) tính toán lượng nước tưới cho cây dưa leo trồng thủy canh đã đi đến kết luận: lượng nước cây sử dụng chỉ chiếm $38 \%$ tổng lượng nước tưới. Tính toán thực tế dựa vào lượng nước trung bình như đề xuất của Pham (2015), thì lượng nước thực tế cần tưới cho cây dưa leo dao động trong khoảng 380 - $456 \mathrm{~mL} / \mathrm{cây} /$ ngày. Bốn lượng nước tưới trong thí nghiệm được tính dựa trên lượng bốt thoát hơi nước của cây dưa leo (ETc), tương đương với lượng nước cần cung ứng cho cây dao động từ 110 - $236 \mathrm{~mL} / \mathrm{cây} /$ ngày tùy từng lượng nước tưới và giai đoạn sinh trưởng của cây. Lượng nước này có thấp hơn lượng nước thực cần cho cây dưa leo trồng thủy canh.

Thí nghiệm không chỉ tập trung vào việc giảm lượng nước tưới mà còn xác định loại giá thể phù hợp nhằm giảm chi phí đầu tư được thực hiện trên cây dưa leo canh tác không đất trong điều kiện nhà lưới. Đối với bốn loại giá thể trồng sử dụng trong thí nghiệm, hỗn hợp 50\% XD + 50\% cát là loại giá thể phù hợp cho cây sinh trưởng và phát triển tốt khi được tưới công thức $120 \%$ ETc, kế đến là loại giá thể kết hợp $50 \% \mathrm{XD}+50 \%$ VĐP hoặc 100\% XD (Bảng 2). Trong khi các loại giá thể kết hợp giữa $50 \% \mathrm{MC}$ và $50 \%$ cát tỏ ra không thích hợp cho cây dưa leo sinh trưởng khi được tưới với bốn lượng nước tưới được áp dụng trong thí nghiệm.

\section{Kết Luận}

Dưa leo được trồng trong giá thể $50 \%$ xơ dừa + 50\% cát và tưới với lượng nước tưới $120 \%$ ETc 
Bảng 4. Ảnh hưởng của lượng nước tưới và giá thể đến năng suất của cây dưa leo

\begin{tabular}{|c|c|c|c|c|c|c|}
\hline \multirow{2}{*}{$\begin{array}{c}\text { Năng suất } \\
\left(\mathrm{kg} / \mathrm{m}^{2}\right)\end{array}$} & \multirow{2}{*}{ Lượng nước tưới (A) } & \multicolumn{4}{|c|}{ Giá thể $(\mathrm{B})$} & \multirow{2}{*}{$\mathrm{TB}_{\mathrm{A}}$} \\
\hline & & $100 \%$ XD & $\begin{array}{c}50 \% \text { XD } \\
+ \\
50 \% \text { VDP }\end{array}$ & $\begin{array}{c}50 \% \mathrm{XD} \\
+ \\
50 \% \mathrm{C}\end{array}$ & $\begin{array}{c}50 \% \mathrm{MC} \\
+ \\
50 \% \mathrm{C}\end{array}$ & \\
\hline \multirow{6}{*}{ Lý thuyết } & $120 \%$ ETc & 8,13 & 8,78 & 8,87 & 5,69 & $7,87^{\mathrm{a}}$ \\
\hline & $100 \%$ ETc & 6,21 & 5,67 & 5,73 & 4,95 & $5,64^{\mathrm{b}}$ \\
\hline & $80 \% \mathrm{ETc}$ & 3,41 & 4,20 & 3,02 & 3,70 & $3,58^{\mathrm{c}}$ \\
\hline & $60 \%$ ETc & 3,49 & 3,34 & 4,35 & 3,25 & $3,61^{\mathrm{c}}$ \\
\hline & $\mathrm{TB}_{\mathrm{B}}$ & $5,31^{\mathrm{a}}$ & $5,50^{\mathrm{a}}$ & $5,49^{\mathrm{a}}$ & $4,40^{\mathrm{b}}$ & \\
\hline & $\mathrm{CV}(\%)=17,82$ & $\mathrm{~F}_{\mathrm{A}}=30,25$ & $* ; \mathrm{F}_{\mathrm{B}}=3,9$ & $* ; \mathrm{F}_{\mathrm{A}} * \mathrm{~B}=$ & $2,22^{\mathrm{ns}}$ & \\
\hline \multirow{6}{*}{ Thực tế } & $120 \% \mathrm{ETc}$ & 7,35 & 6,95 & 7,50 & 4,89 & $6,67^{\mathrm{a}}$ \\
\hline & $100 \%$ ETc & 5,03 & 4,52 & 5,05 & 3,36 & $4,49^{\mathrm{b}}$ \\
\hline & $80 \%$ ETc & 3,16 & 3,39 & 2,33 & 2,23 & $2,78^{\mathrm{bc}}$ \\
\hline & $60 \%$ ETc & 2,81 & 2,61 & 2,26 & 1,89 & $2,39^{\mathrm{c}}$ \\
\hline & $\mathrm{TB}_{\mathrm{B}}$ & $4,59^{a}$ & $4,37^{a}$ & $4,29^{a}$ & $3,09^{b}$ & \\
\hline & $\mathrm{CV}(\%)=15,42$ & $\mathrm{~F}_{\mathrm{A}}=26,20^{*}$ & $; \mathrm{F}_{\mathrm{B}}=13$ & $* * ; \mathrm{F}_{\mathrm{A}}{ }^{*} \mathrm{~B}$ & $=1,99^{\mathrm{ns}}$ & \\
\hline \multirow{6}{*}{ Thương phẩm } & $120 \%$ ETc & 7,32 & 6,76 & 7,48 & 4,77 & $6,58^{\mathrm{a}}$ \\
\hline & $100 \%$ ETc & 4,85 & 4,43 & 4,83 & 3,32 & $4,36^{\mathrm{b}}$ \\
\hline & $80 \%$ ETc & 2,87 & 3,17 & 2,11 & 1,99 & $2,53^{\mathrm{bc}}$ \\
\hline & $60 \%$ ETc & 2,29 & 2,17 & 1,67 & 1,37 & $1,88^{\mathrm{c}}$ \\
\hline & $\mathrm{TB}_{\mathrm{B}}$ & $4,33^{\mathrm{a}}$ & $4,13^{\mathrm{a}}$ & $4,02^{\mathrm{a}}$ & $2,86^{\mathrm{b}}$ & \\
\hline & $\mathrm{CV}(\%)=15,8$ & $\mathrm{~F}_{\mathrm{A}}=31,13$ & $* ; \mathrm{F}_{\mathrm{B}}=14$ & $* * \mathrm{~F}_{\mathrm{A}} * \mathrm{~B}$ & $=2,25^{\mathrm{ns}}$ & \\
\hline
\end{tabular}

a-c Trong cùng một hàng hoặc cột, các chữ số có cùng ký tự theo sau khác biệt không có ý nghĩa thống kê. ns: Khác biệt không có ý nghĩa về mặt thống kê $(P>0,05)$; $^{*}$ : khác biệt có ý nghĩa về mặt thống kê $(P<0,05)$; **: khác biệt rất có ý nghĩa về mặt thống kê $(P \leq 0,01)$.

Bảng 5. Ảnh hưởng của bốn lượng nước tưới và giá thể đến hiệu quả kinh tế của cây dưa leo canh tác không đất

\begin{tabular}{|c|c|c|c|c|c|}
\hline & \multirow{2}{*}{$\begin{array}{c}\text { Lượng nước tưới } \\
(\mathrm{A})\end{array}$} & \multicolumn{4}{|c|}{ Giá thể $(\mathrm{B})$} \\
\hline & & $100 \%$ XD & $\begin{array}{c}50 \% \mathrm{XD} \\
+ \\
50 \% \mathrm{VDP}\end{array}$ & $\begin{array}{c}50 \% \mathrm{XD} \\
+ \\
50 \% \mathrm{C}\end{array}$ & $\begin{array}{c}50 \% \mathrm{MC} \\
+ \\
50 \% \mathrm{C}\end{array}$ \\
\hline & $120 \% \mathrm{ETc}$ & 109.800 .000 & 101.400 .000 & 112.200 .000 & 71.550 .000 \\
\hline Tổng thu & $100 \%$ ETc & 72.750 .000 & 66.450 .000 & 72.450 .000 & 49.800 .000 \\
\hline \multirow{3}{*}{ (đồng/1.000m²/vụ) } & $80 \%$ ETc & 43.050 .000 & 47.550 .000 & 31.650 .000 & 29.850 .000 \\
\hline & $60 \%$ ETc & 34.350 .000 & 32.550 .000 & 250.500 .000 & 20.550 .000 \\
\hline & $120 \%$ ETc & 52.211 .312 & 53.651 .320 & 40.461 .254 & 29.127 .864 \\
\hline Tổng chi & $100 \%$ ETc & 51.357 .548 & 52.797 .555 & 39.607 .490 & 28.274 .100 \\
\hline \multirow{3}{*}{ (đồng/1.000 m²/vụ) } & $80 \%$ ETc & 50.501 .464 & 51.941 .471 & 38.751 .405 & 27.418 .015 \\
\hline & $60 \%$ ETc & 49.636 .100 & 51.076 .107 & 37.886 .041 & 26.552 .651 \\
\hline & $120 \%$ ETc & 57.588 .687 & 47.748 .680 & 71.738 .746 & 42.422 .136 \\
\hline & $100 \%$ ETc & 21.392 .452 & 13.652 .445 & 32.842 .510 & 21.525 .900 \\
\hline \multirow{2}{*}{ (đồng/1.000m²/vụ) } & $80 \%$ ETc & -7.451 .464 & -4.391 .471 & -7.101 .405 & 2.431 .985 \\
\hline & $60 \%$ ETc & -5.286 .100 & -18.526 .107 & -12.836 .041 & -6.002 .651 \\
\hline \multirow{4}{*}{ Tỷ suất lợi nhuận } & $120 \%$ ETc & 1,10 & 0,89 & 1,77 & 1,46 \\
\hline & $100 \%$ ETc & 0,42 & 0,26 & 0,83 & 0,76 \\
\hline & $80 \%$ ETc & - & - & - & 0,09 \\
\hline & $60 \%$ ETc & - & - & - & - \\
\hline
\end{tabular}

Giá bán dưa leo 15.000 đồng/kg. 
(226 mL/cây/ngày ở giai đoạn 3 tuần sau trồng, $280 \mathrm{~mL} /$ cây/ngày cho giai đoạn $3-5$ tuần sau trồng và $236 \mathrm{~mL} /$ cây/ngày giai đoạn sau 5 tuần trồng) có năng suất thực thuvà năng suất thương phẩm cao nhất $\left(7,50 \mathrm{~kg} / \mathrm{m}^{2}\right.$ và $\left.7,48 \mathrm{~kg} / \mathrm{m}^{2}\right)$ và đạt hiệu quả kinh tế cao nhất (71.738.746 đồng/1.000 $\mathrm{m}^{2}$, tỷ suất lợi nhuận đạt 1,77$)$.

\section{Tài Liệu Tham Khảo (References)}

Böhme, M., Hoang, L. T., \& Vorwerk, R. (2001). Effect of different substrates and mineral as well as organic nutrition on the growth of cucumber in closed substrate systems. Acta Horticulturae 548, 165-172.

FAO (Food and Agriculture Organization of the United Nations). (2005). A system of integrated agricultural censuses and surveys, Volome 1. World programme for the census of agriculture 2010. Rome, Italy: FAO.

FAO (Food and Agriculture Organization of the United Nations). (1992). Soilless cultivation in horticulture. Ha Noi, Vietnam: FAO.

Gomez, K. A., \& Gomez, A. A. (1984). Statistical procedures for agricultural research. New Jersey, USA: John Wiley \& Sons.

Grewal, H. S., Maheshwari, B., \& Parks, S. E. (2011). Water and nutrient use efficiency of a lowcost hydroponic greenhouse for a cucumber crop: An Australian case study. Agricultural Water Management 98(5), 841-846.

Islam, S., Khan, S., Ito, T., Maruo, T., \& Shinohara, Y. (2002). Characterization of the physico-chemical properties of environmentally friendly organic substrates in relation to rockwool. The Journal of Horticultural Science and Biotechnology 77(2), 143-148.
Nguyen, N. T. (2016). Effects of seed quality and planting spaces on growth, development and productivity of cucumber (Cucumis sativus L.) in soilless cultivation model in Ho Chi Minh City (Unpublished master's thesis). Nong Lam University, Ho Chi Minh City, Vietnam.

Nguyen, U. H., \& Nguyen, T. B. (2009). Effects of substrates and hydroponic nutrient media on Polianthes tuberosa L. from tissue culture. Can Tho University Journal of Science 11, 146-156.

Olle, M., Ngouajio, M., \& Siomos, A. (2012). Vegetable quality and productivity as influenced by growing medium: a review. Agriculture 99(4), 399-408.

Pham, V. P. (2015). Effects of four nutrient formulas on growth, development and productivity of cucumber (Cucumis sativus L.) in soilless cultivation model in Ho Chi Minh City (Unpublished master's thesis). Nong Lam University, Ho Chi Minh City, Vietnam.

Resh, H. M. (2012). Hydroponic food production: A definitive guidebook for the advanced home gardener and the commercial hydroponic grower. Florida, USA: CRC Press.

Schröder, F. G., \& Lieth, J. H. (2002). Irrigation Control in Hydroponics. In Savvas, D., \& Passam, H. (Eds.) Hydroponic Production of Vegetables and Ornamentals (263-298). Athens, Greece: Embryo Publications.

Tran, B. T., Bui, T. V., \& Tran, L. N. (2009). Effects of different substrates, varieties, nutrient solutions on growth and yield of hydroponic lettuce, winter-spring 2007-2008. Can Tho University Journal of Science 11, 339-346. 